\title{
Premature collagen fibril formation, fibroblast-mast cell interactions and mast cell mediated phagocytosis of collagen in keloids
}

Sandra Arbi ${ }^{1}$, Ehren Cronje Eksteen ${ }^{2}$, Hester Magdalena Oberholzer ${ }^{1}$, Helena Taute ${ }^{1}$, Megan

Jean Bester ${ }^{1}$

${ }^{1}$ Department of Anatomy, Faculty of Health Sciences, University of Pretoria, South Africa

${ }^{2}$ Division of Plastic Surgery, Steve Biko Academic Hospital, University of Pretoria, South Africa

Corresponding author:

MJ Bester

Department of Anatomy

Faculty of Health Sciences

University of Pretoria

Private Bag $\times 323$

ARCADIA, 0007

SOUTH AFRICA.

Email: megan.bester@up.ac.za

Tel: (+27)12 3192632 / Fax: (+27)12 3192240

\begin{abstract}
Keloids are benign hyper-proliferative growths of fibrous tissue, where increased fibroblast activity results in abnormal collagen deposition. Excessive inflammation is a characteristic feature of keloids but little is known about the underlying ultrastructural features of keloids related to collagen processing, fibril and fibre formation, the interaction between fibroblasts and associated collagen fibres and mast cells. In this study, the ultrastructure of the dermis of keloid patients was evaluated using light and transmission electron microscopy techniques. Abnormal intracellular premature collagen fibril formation was observed. Phagocytosis of collagen fibrils by mast cells was a common ultrastructural feature of keloid tissue as was a close or direct
\end{abstract}


association between fibroblasts and mast cells. Based on these findings and recent advances in knowledge related to collagen synthesis, fibril formation and processing we hypothesise that keloid formation is primary due to abnormal collagen synthesis where the consequent accumulation of collagen fibres causes increased mast cell recruitment and collagen phagocytosis. Subsequent release of mast cell derived mediators then promotes further collagen synthesis. The observation of early formation in keloid tissue of premature insoluble collagen fibrils supports previous studies that enzymes such as procollagen C-proteinase are important early therapeutic targets.

Keywords: Collagen, intracellular, fibre, fibroblast, keloid, mast cell

\section{Introduction}

Keloids are benign hyper-proliferative growths of fibrous tissue that may develop spontaneously or as a result of an abnormal healing after cutaneous injury. Keloids do not regress on their own, and often continue to grow beyond the original wound margins and the removal thereof often results in reoccurrence and difficulty in treatment [1-3]. The areas of the body most commonly associated with keloids include the chest, shoulders, upper back, back of the neck and earlobes [4]. Increase prevalence has been reported in African and Asian populations [5] while genetic factors, puberty, gender and pregnancy is associated with an increased probability of keloid formation $[1,6,7]$. Currently, there is no single effective treatment for keloids $[1,8]$ and the identification of new therapeutic targets is an important focus of research.

Histologically, keloids are characterised by the presence of inflammatory cells such as mast cells and macrophages with a greatly expanded dermis being occupied by collagen fibers and fibroblasts [9]. Mast cells are present in the dermal and subcutaneous tissue layers of the skin and are an important cellular component of the innate immune system. Through a process of 
phagocytosis and reactive oxygen species production accompanied with degranulation, mast cells protect tissue against pathogens.

Increased numbers of dermal mast cells are seen in systemic fibrosis and other fibrotic disorders such as chronic graft vs. host disease and lung fibrosis [10-12]. Due to the presence and increased serum $\lg E$ associated with keloids, keloid formation may likely be associated with mast cell hypersensitivity. Also, patients with allergy symptoms were seen to have a greater number of keloids than patients without allergy, possibly linking keloids to mast cell activity [13, 14].

Also, in a recent study by Bakry and co-workers the authors investigated the possible role of hematopoietic stem cells in keloid pathogenesis by detecting these cells in keloid tissue by using immunohistochemistry. The authors used CD34 and c-KIT, antibodies specific for hematopoietic stem cell markers and found an up regulation of these markers in keloid tissue compared with controls, indicating a possible role of hematopoietic stem cells in the formation of keloids [15].

Another important cell type involved in keloid formation is the dermal fibroblast which is responsible for collagen production. Collagen synthesis and fibrogenesis is a complex process with distinctive intra- and extracellular phases. In keloids overproduction of collagen only occurs at the wound site whereas systemic sclerosis is associated with the progressive thickening and fibrosis of the skin. In this disorder it was observed that mast cells directly activate fibroblasts via gap junctions resulting in increased collagen production [16]. Mast cells release several growth factors such as transforming growth factor (TGF)- $\beta$, fibroblast growth factor (FGF), cytokines as well as other factors such as angiogenesis factor and mitotic polypeptide that 
stimulate collagen formation by dermal fibroblasts resulting in the development of dermal fibrosis [17-19].

Likewise after injury, mast cell infiltration is believed to promote keloid development through the stimulation of fibroblast activity. Mast cells and fibroblast may interact via gap junctions and release cytokines. It has been suggested that this interaction may cause fibroblasts to over produce collagen in the connective tissue of the skin $[16,20]$.

Excessive inflammation and overproduction of collagen by fibroblasts is an accepted feature of keloids but information related to the underlying ultrastructural features of keloids related to collagen processing, fibril and fibre formation, the interaction between fibroblasts and associated collagen fibres and mast cells is limited. Using light and transmission electron microscopy techniques this study endeavours to provide more detailed information regarding these processes and cellular interactions in keloid tissue.

\section{Materials and Methods}

Keloid and normal (excess skin from skin transplantation) skin samples were obtained from a plastic surgeon at Steve Biko Academic Hostpital in Pretoria, South Africa. Ethical approval for the collection of skin was obtained from the research ethics comittee at the University of Pretoria (protocol number 336/2014). Three control and eight keloid samples were used.

\section{Light Microscopy (LM)}

Normal and keloid skin samples were fixed in $4 \%$ formaldehyde and dehydrated in a series of increasing ethanol concentrations, followed by infiltration and embedding in paraffin wax. Sections of $3-5 \mu \mathrm{m}$ were prepared and stained with Picrosirius Red and viewed with polarised light to differentiate between collagen fibre types [21, 22]. 


\section{Transmission Electron Microscopy (TEM)}

The skin samples were fixed in $2.5 \%$ glutaraldehyde/formaldehyde in $0.075 \mathrm{M}$ sodium phosphate buffer $(\mathrm{pH}=7.4)$, rinsed three times in the same buffer before it was placed in the secondary fixative, $1 \%$ osmium tetroxide solution for one hour. Following secondary fixation, the samples were rinsed again as described above. The samples were then dehydrated in $30 \%, 50 \%, 70 \%$, $90 \%$ and three changes of $100 \%$ ethanol and were embedded in resin. Ultra-thin sections (70$100 \mathrm{~nm})$ were cut with a diamond knife using an ultramicrotome. Samples were then contrasted with uranyl acetate and lead citrate, after which it was examined with a JEOL transmission electron microscope (TEM) (JEM 2100F).

\section{Results}

To investigate the underlying ultrastructural features of keloids related to collagen processing, fibril and fibre formation, the interaction between fibroblasts and associated collagen fibres and mast cells the general characteristics of collagen fibre arrangement in normal and keloid tissue was determined.

Figures $1 \mathrm{a}-\mathrm{f}$ are normal (a-c) and keloid skin (d-f) viewed with polarised light, indicating the differences in fibre presence and thickness. Both type I collagen (orange red birefringence) (solid arrow in Fig. $1 \mathrm{c}$ ) and type III collagen (green yellow birefringence) (dashed arrow in Figure $1 \mathrm{c}$ ) was present in normal skin. Only type I collagen indicated by the presence of orange red birefringent collagen fibres was found in keloid tissue (Fig. $1 \mathrm{f}$ ). 


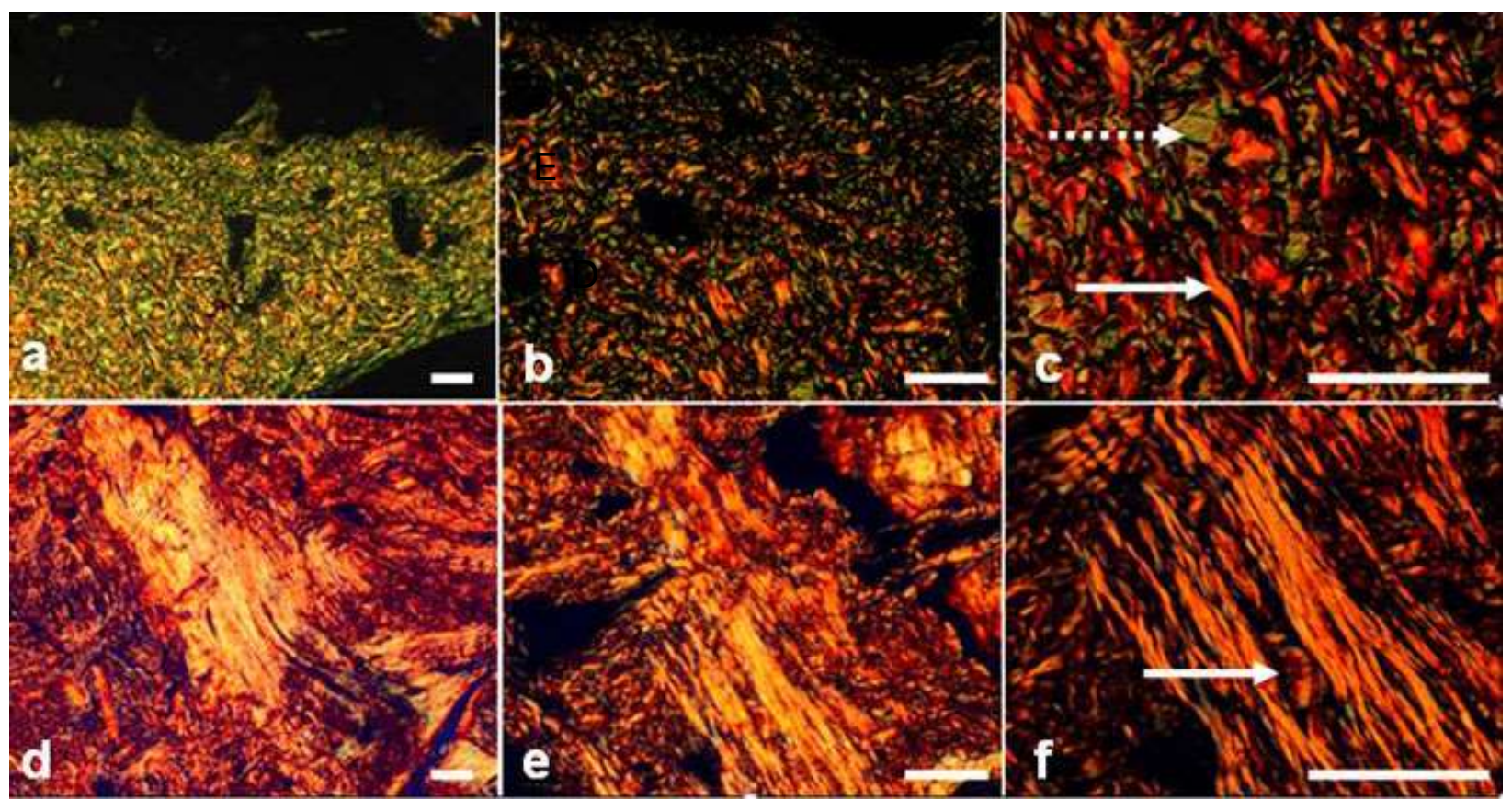

Figure 1: Increasing magnifications of normal (Figures a-c) and keloid (Figures $d-f$ ) tissue stained with PR and viewed with polarised light, showing difference- in appearance and colour distribution of the collagen fibres. White solid arrows indicate Type 1 collagen fibres and dashed arrow indicates Type III collagen fibres (Scale bar=20 $\mu$ m).

The ultrastructure of keloid tissue was then further evaluated using TEM. Firstly, the general morphology and arrangement of fibres in keloid tissue was evaluated. Figure $2(a$ and $b)$ are TEM micrographs of normal and keloid skin respectively, showing a fibroblast and associated collagen fibres. The appearance of collagen in the extracellular matrix (ECM) of normal skin (Fig. 2 a) and keloid skin (Fig. 2 b) differs. In normal skin collagen fibres have a finer fibrillar structure while keloid collagen fibres are larger and lack the fibrillar appearance of short individual collagen fibres. At a higher magnification, Figure 4 and 5 shows the presence of intracellular collagen fibrils similar in size and shape as the fibres present in the ECM of keloid tissue. 


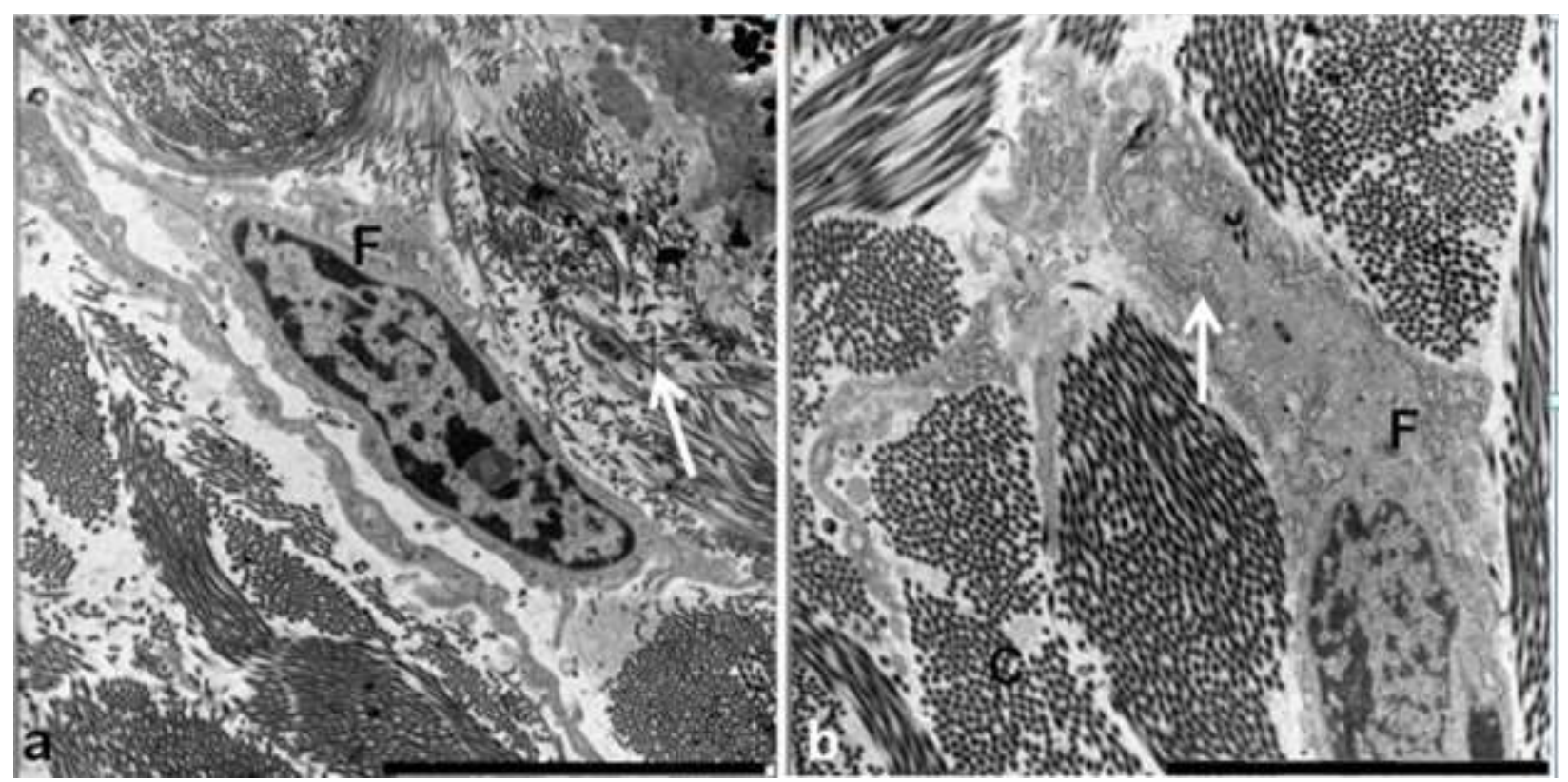

Figure 2: (a) TEM micrograph of normal skin indicating a fibroblast (F) with fibrillar collagen (arrow) and (b) keloid skin with thicker and non fibrillar collagen $(\mathrm{C})$ and active protein synthesis due to visible rough endoplasmic reticulum in the cytoplasm (arrows). (Scale bar $=5 \mu \mathrm{m})$

Fibroblasts presenting with collagen in the cytoplasm also had extremely well developed rough endoplasmic reticulum (RER) with large numbers of ribosomes (Fig. 3b, black arrow). This morphology is indicative of fibroblast activation and increased protein synthesis. Vesicles containing collagen are evident at a higher magnification in close proximity to Golgi apparatus (Fig. 3b, white arrow). 


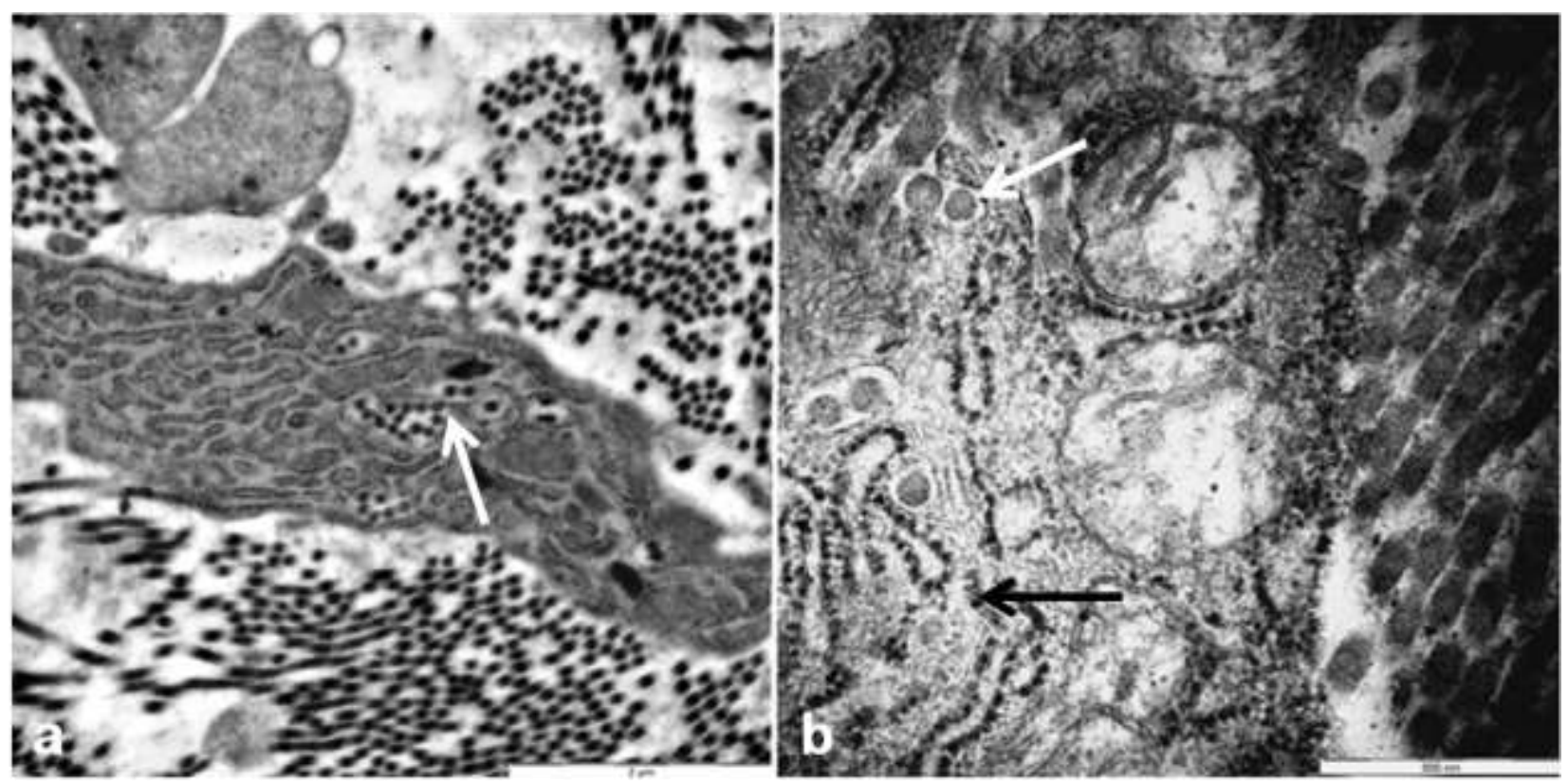

Figure 3: (a) TEM micrograph showing the presence of intracellular collagen fibres in a keloid fibroblast (white arrow); (b) Higher magnification shows activation of fibroblasts indicated by abundant ribosomes (black arrow) as well as presence of collagen fibres in vesicles (white arrow) [Scale bars $(a)=2 \mu \mathrm{m},(b)=500 \mathrm{~nm}$ ].

The formation and release of collagen fibres are shown in the TEM micrographs in Figure 4 (ad). Figure 4a shows collagen formation and release as single (black arrow) and grouped (white arrow) fibrils. In Figure 4b, various stages of collagen formation and maturation are indicated. These stages can be identified by the thickness of the collagen fibrils (white arrows in Figure $4 \mathrm{~b}$ and d) and the extent of collagen fibril aggregation (Fig. $4 \mathrm{c}$ and d). Figure $4 \mathrm{~d}$ also clearly shows the fusion of vesicles containing collagen fibrils (white arrow) and the release of collagen fibre to the ECM (black arrow).

In Figures $5(a-f)$, the association of mast cells with fibroblasts are shown. In Figure 5 ( $a$ and $b$ ) a mast cell $(\mathrm{M})$ is in close proximity to a fibroblast $(\mathrm{F})$ within a region of densely arranged and packed collagen fibers. In Figure 5 (c-f) this association can be seen on higher magnification, where the mast cell and fibroblast are in direct cell-to-cell contact indicated by the arrows [Fig 5e (white arrow) and Fig 5f (black arrow)]. 


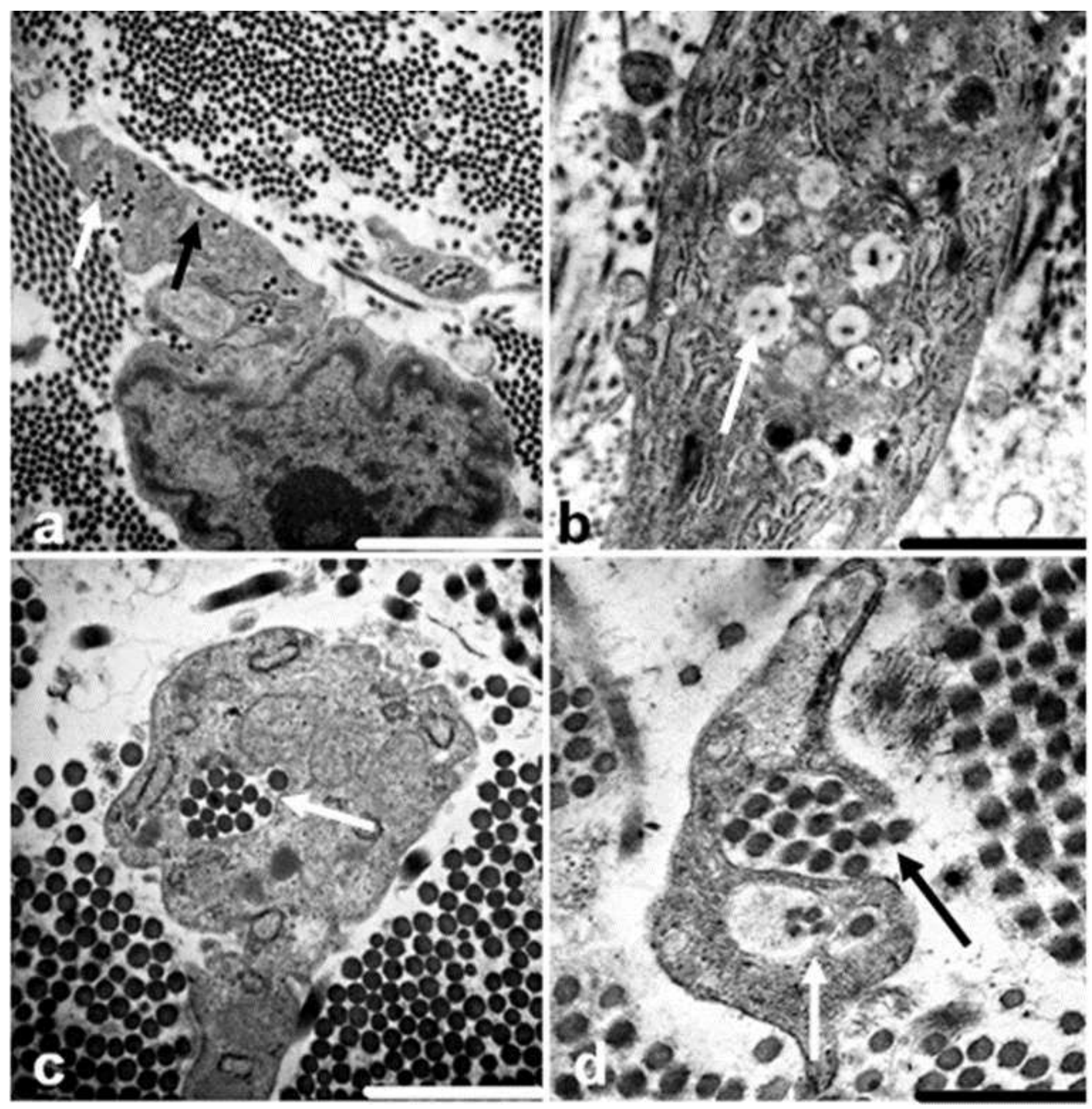

Figure 4:(a) Collagen formation and release as single (black arrow) and grouped (white arrow) fibrils (b) collagen formation and maturation identified by the presence of fibrils with a thinner diameter (arrow) (c) aggregated collagen fibrils forming an intracellular fibre (arrow) in fibroblast and (d) collagen vesicle fusion (white arrow) and release of

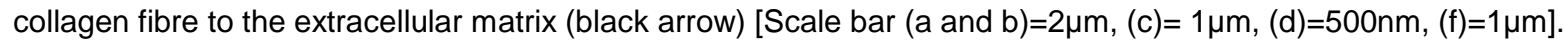



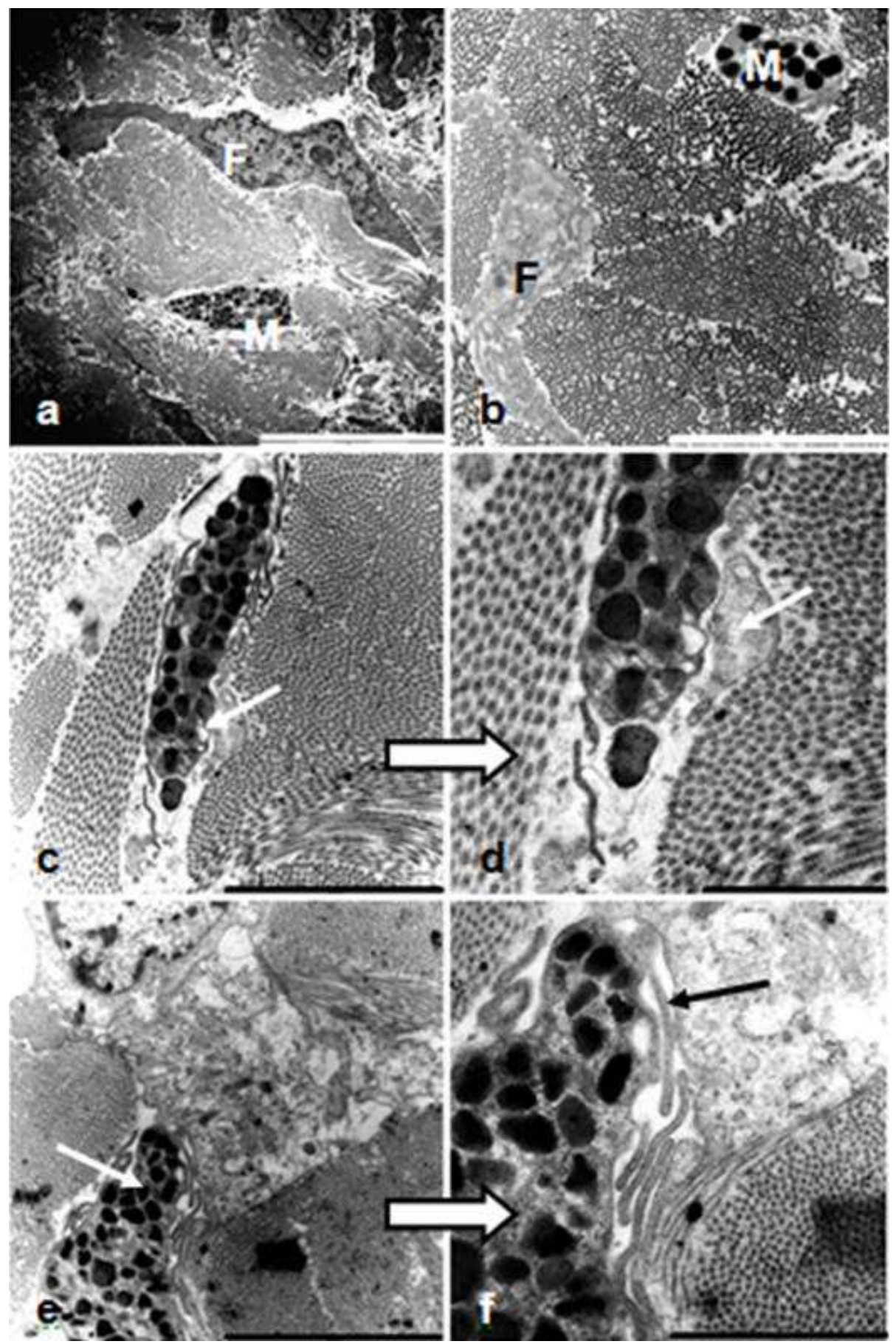

Figure 5: $(a$ and $b)$ Mast cell $(M)$ and keloid fibroblast $(F)$ in close proximity to each other in different keloid samples.

(c and d) Mast cells and fibroblast cell-to-cell contact (white arrows), and (e and f) at higher magnification [Scale bar $(a)=5 \mu \mathrm{m} ;(b)=10 \mu \mathrm{m} ;(\mathrm{c})=2 \mu \mathrm{m},(\mathrm{d}$ and $\mathrm{e})=5 \mu \mathrm{m},(\mathrm{f})=2 \mu \mathrm{m}]$. 
In Fig. 6 a mast cell is engulfing a bundle of collagen fibres (black arrow). Another bundle of collagen fibres is seen in close proximity to the cell membrane of the mast cell. The presence of a slight indentation in the membrane (white arrow) around a collagen bundle indicates that this cell is preparing to engulf the collagen. Smaller groups of collagen fibres are present in the cytoplasm of the mast cell (thin white arrows). Degranulation of the mast cell is evident by the presence of lighter coloured granules along with the normal granules as seen in this figure.

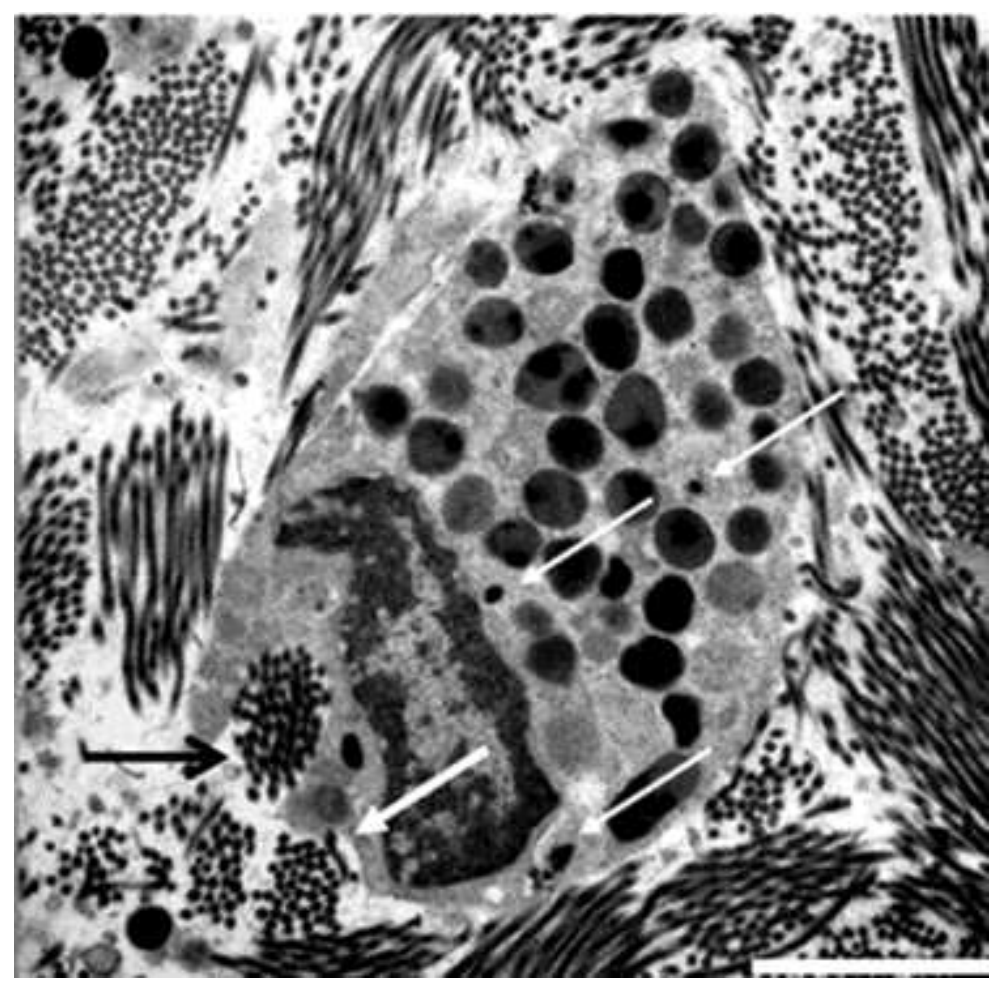

Figure 6: TEM micrograph of the internal structure of mast cell showing the phagocytosis of collagen (black arrow) and cytoplasmic indentation (thick white arrow) preparing for phagocytosis. Smaller groups of collagen fibres are seen (thin white arrows). (Scale bar=2 $2 \mu \mathrm{m})$.

\section{Discussion}

Type I collagen is found in fibrous supporting tissue, the dermis of the skin, tendons, ligaments and bone. It may be arranged loosely or densely depending on the mechanical support required 
by the tissue [6]. Type III collagen is found in the reticulum, and is present in highly cellular tissue such as the liver, bone marrow and lymphoid organs [6]. Normal adult skin contains about $80 \%$ type I and $20 \%$ type III collagen.

In this study, light microscopy with PR staining revealed the typical over deposition of type I collagen which is a characteristic feature of keloid tissue (Fig. $1 \mathrm{~d}$-f) as has been described by Shaker et al., 2011 [23]. TEM analysis revealed closely packed fibrils within densely arranged large fibres within the ECM. In contrast, in normal skin the fibrils are more loosely arranged and fibrillar (Fig. 2a, b). The presence of fully formed collagen fibrils and fibre aggregates in fibroblasts demonstrates premature fibril formation and subsequent processing. To our knowledge this is the first study that has observed this phenomenon in keloids and the intracellular presence of insoluble collagen fibrils identified by TEM has only been described for chick embryo tendon formation [24].

Normal collagen synthesis has an intracellular and an extracellular component as shown in Figure 7. Intracellularly collagen mRNA is synthesised in the nucleus, and transported to the RER [25] where the collagen is produced. Early post-translational modification includes hydroxylation and glycosylation. The presence of the non-helical domains associated with each collagen, the propeptide domains at the $\mathrm{C}$ - and $\mathrm{N}$-terminals [26] play an important role in the collagen triple helical formation [27] (Fig. 7, Step 1). The C-propeptide determines chain selection and direct chain association during intracellular assembly of the procollagen molecules [28]. The presence of these propeptide sequences ensures that the large procollagen molecule remains soluble. In the Golgi apparatus the procollagen undergoes further post translational modifications which involve further glycosylation steps (Fig. 7, Step 2). The soluble pro-collagen is then transported via transport vesicles to the cell surface where it is then secreted into the extracellular space [25] (Fig. 7, Step 3). 


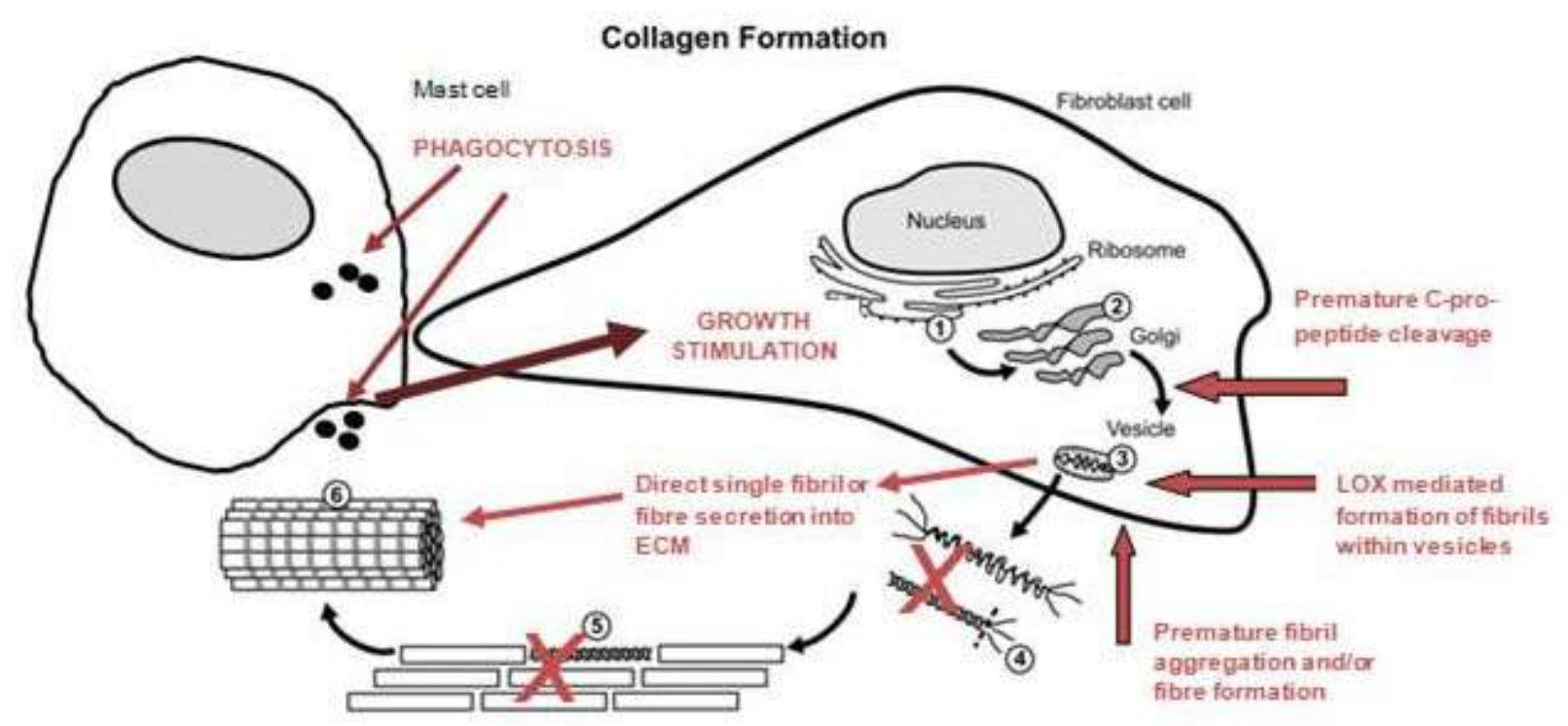

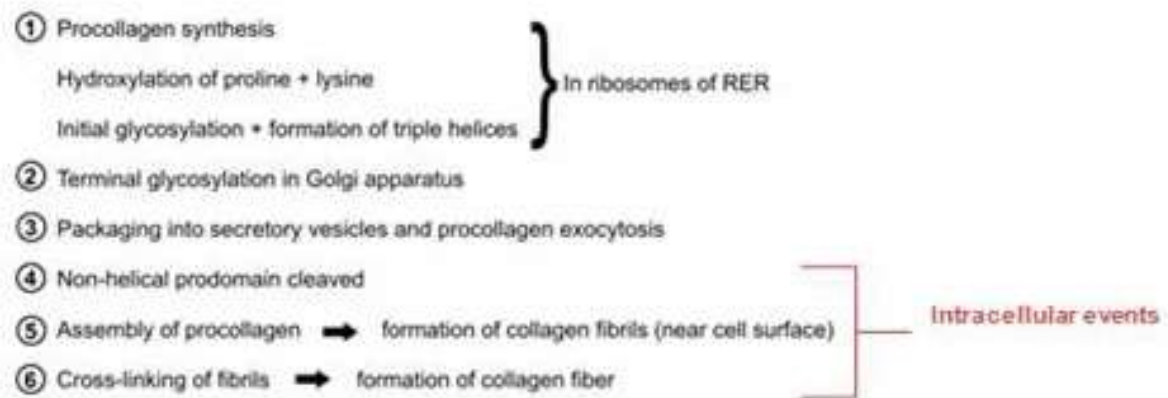

Figure 7: Schematic diagram of normal and abnormal keloid collagen processing.

Following or during secretion into the ECM (Fig.7, Step 4), processing and associated proteolytic removal of the $\mathrm{N}$ - and $\mathrm{C}$ - collagen propeptides occurs, catalysed by specific $\mathrm{N}$ - and C- proteinases (PCP) [29]. The C-terminal ensures the intracellular solubility while the $\mathrm{N}$ propeptide influences the shape and diameter of the fibril [30]. Once these sequences are removed collagen becomes insoluble and fibrogenesis occurs [29].

The insoluble collagen which then assembles into fibrils (Fig. 7, Step 5), that are structurally stabilised by cross links (Fig. 7, Step 6) [26, 31] are catalysed by lysyl oxidase (LOX). Besides 
stabilisation of the collagen structure, the intra- and intermolecular links increase the tensile strength of the final collagen fibre. It is believed that these peptides then re-enter the cell and regulate collagen production by a feedback mechanism [26].

The presence of insoluble collagen fibrils within the Golgi apparatus and secretory vesicles (Fig.3 and 4) implies collagen processing in keloid fibroblast is defective and this may be related to increased PCP activity which results in premature collagen fibril formation. As mentioned previously the C- terminal propeptide sequence ensures the solubility of intracellular collagen. Normally this sequence is only removed once the procollagen is secreted into the ECM (Fig. 7; Step 6). Premature or early removal of this sequence would result in decreased solubility and rapid crosslink formation by LOX. PCP also processes LOX to its active form, therefore as a consequence increased levels of PCP also results in increased LOX levels and as a consequence rapid fibril formation. Broder et al. (2013) have identified that metalloproteases $\alpha$ and $\beta$-meprin are $\mathrm{C}$ - and $\mathrm{N}$ - procollagen proteinases [32]. Both meprins are expressed by human dermal fibroblasts and remove the $\mathrm{C}$ - and $\mathrm{N}$ - propeptides from collagen type I and III. Expression of $\alpha$ - and $\beta$-meprin is increased in keloids [32]. Both Turtle et al. (2012) and Broder et al. (2013) have identified PCP and the meprins as possible therapeutic targets for fibrosis and possibly keloid formation [32, 33]. The cause of increased levels of PCP and subsequently of LOX is unknown although increased LOX levels are associated with hypoxia and the expression of hypoxia-inducible factor-1 $\alpha$, an important microenvironment factor in the development of fibrosis. A shown in Fig $2 \mathrm{~b}$ and Figure 5, fibroblasts due to overcrowding by collagen fibers, can be assumed to be in a hypoxic environment which would result in increased LOX levels possibly as a result of increased PCP.

In wound healing and fibrosis-associated conditions the number and the distribution of mast cells is increased. Various authors reported the increased presence of mast cells in keloid tissue $[13,18,19,34-38]$. In this study, TEM analysis revealed the presence of mast cells in close 
proximity to fibroblasts (Fig. $5 \mathrm{a}$ and b) which could indicate stimulation of fibroblasts via cytokines [19] and growth factors such as basic fibroblast growth factor (bFGF), TGF- $\beta$ [18, 39]. TGF- $\beta$ also stimulates the production LOX. The presence of vacuoles and intact cell granules in a mast cell is characteristic of normal and non-active mast cells. Degranulation as seen in Fig 6 (lighter stained granules) is indicative of mast cell activity and a release of histamine, heparin and other factors [40].

Direct contact between fibroblasts and mast cells through gap junctions is also a possible means of association [16]. Moyer et al. (2004) identified the presence of gap junction intercellular communication between mast cells and fibroblasts and that this interaction only occurred in vitro when these cells were cultured in a three dimensional environment [20]. Cellto-cell or direct contact between mast cells and fibroblasts in vivo was observed during TEM analysis (Fig. 5 c-f). Associations of mast cells with fibroblasts have previously been identified as an important feature of fibrotic conditions such as systemic sclerosis, chronic graft vs. host disease and lung fibrosis characterised by an overproduction of collagen by fibroblasts [12, 41 , 42]. In pulmonary fibrosis mast cells were observed in partial degranulation and in close proximity to lung fibroblasts [43, 44]. A study on systemic sclerosis [16], cell-to-cell contact between mast cells and fibroblasts was observed but the authors were unable to determine whether the contact was a characteristic specific to systemic sclerosis or due to mast cell activation. In this study cell-to-cell contact between fibroblasts and mast cells was also observed, indicating together with findings of other authors related to other types of fibrosis, this type of interaction is a common feature of fibrosis.

It is unknown whether the increased presence of mast cells is a consequence of overproduction of collagen i.e. an excess collagen in the ECM causes increased homing and/or migration of mast cells into the dermis into areas of increased collagen production. Alternatively the increased presence of mast cells due to inflammation and the consequent release of cytokines 
or growth factors results in increased fibroblast proliferation. A recent study by Willenborg et al. (2014) has shown that genetic ablation of connective tissue type mast cells fails to prevent bleomycin induced lung fibrosis [45]. Keloid fibroblasts have been isolated from keloid tissue and grown in cell culture; compared to normal cells keloid fibroblasts have shown differences in growth properties and gene expression [46, 47]. Furthermore epigenetic changes have been implicated in the development of fibrosis in keloids [48]. Recently Mastri et al. (2013) have identified Frizzled-related protein 2 (sFRP2) as an important mediator of fibrosis, as this protein enhances procollagen $\mathrm{C}$ proteinase activity and this leads to increased procollagen processing and deposition in cardiac fibrosis [49]. Similarly SFRP2 could also have a similar role in keloid formation and this protein may, as for other types of fibrosis, be a specific target of therapeutic intervention [49]. Smith et al. 2008 have reported that keloid fibroblasts growth in cell culture has more than a fivefold reduction in the expression of sFRP2 [47]. This however, may be due to differences between an in vitro and an in vivo environment where in vivo environmental and cellular factors such as hypoxia and interactions with other cell types may alter gene expression.

Phagocytosis of collagen fibrils by mast cells (Fig. 6) may indicate that mast cells in keloid tissue play an important role in maintaining tissue homeostasis and turnover. The presence of collagen fibres in mast cells of keloids has also been reported by Ehrlich et al. (1994) and these authors hypothesised that this was related to an immunological dysfunction [35]. In contrast we believe, supported by recent scientific literature $[32,33,50]$, that keloid formation is primary due to a defect in collagen synthesis and increased mast cell accumulation is a consequence of collagen overproduction or content in the dermis. As a consequence, in an endeavour to reduce the amount of collagen by phagocytosis, growth factors and mediators are released that further stimulate fibroblasts to produce more collagen. 


\section{Conclusion}

In conclusion this study clearly identifies keloid formation as a defect of procollagen synthesis and processing. Phagocytosis of collagen by mast cells indicates that accumulation of these cells may be a secondary effect to excessive collagen synthesis. In addition, the release of interleukins, mediators and growth factors may further stimulate collagen fibril formation with the imbalance towards increased synthesis. This study also identifies and confirms the findings of other studies that procollagen C-proteinase is an important therapeutic target [32, 33].

\section{Declaration of interest}

The authors report no conflict of interest. The authors alone are responsible for the content and writing of the paper.

\section{References}

1. Al-Attar A, Mess S, Thomassen JM, Kauffman CC, Davidson SP. Keloid pathogenesis and treatment. Plast Reconstr Surg 2009; 117: 286-300.

2. Butler PD, Longaker MT, Yang GP. Current progress in keloid research and treatment. J Am Coll Surg 2008; 206: 731-741

3. Robles DT, Berg D. Abnormal wound healing: Keloids. Clin Dermatol 2007; 25: 26-32.

4. Bayat A, Arscott G, Ollier WER, Ferguson MWJ, McGrouther DA. Description of site-specific morphology in an Afrocaribbean population. British Assoc Plast Surg 2004; 57: 122-133.

5. Hellstrőm M, Hellstrőm S, Engstrőm-Leurent A, Bertheim U. The structure of the basement membrane zone differs between keloids, hypertrophic scars and normal skin: J Plast Reconstr Aesthetic Surg 2014; In press.

6. Young B, Heath JW. Wheater's Functional Histology, A text and colour Atlas. $5^{\text {th }}$ ed. USA: Elsevier Limited; 2006 
7. Tuan T, Zuh JY, Sun B, Nichter LS, Nimni MF, Laug WE. Elevated levels of plasminogen activator inhibitor-1 may cccount for the altered fibrinolysis by keloid fibroblasts. J Invest Dermatol 1996; 106:1007-1011.

8. Kelly, Clay M. Skin Disorders and Their Management. Prosthetics and Patient Management: $A$ Comprehensive Clinical Approach (2006): 53.

9. Bran GM, Goessler UR, Hormann K, Riedel F, Sadrick H. Keloids: Current concepts of pathogenesis (Review) Int J Molec Med 2009;24: 283-293.

10. Lee Choi K, Claman HN. Mast cells, fibroblasts and fibrosis. New clues to the riddle of mast cells. Immunol Res. 1985; 6: 145-152.

11. Hawkins RA, Claman HN, Clark RAF, Steigerwald JC. Increased dermal mast cell populations in progressive systemic sclerosis: A link in chronic fibrosis? Ann Intern Med 1985;102: 182-186.

12. Ozbilgin MK, Inan $S$. The roles of transforming growth factor type $\beta_{3}$ (TFG- $\left.\beta_{3}\right)$ and mast cells in the pathogenesis of scleroderma. Clin Rheumatol. 2003; 22: 189-195.

13. Smith CJ, Smith JC, Finn MC. The possible role of mast cells (allergy) in the production of keloid and hypertrophic scarring. J Burn Care Rehabil 1987;8: 126-131.

14. Mouhari-Toure A, Saka B, Kombate K, Akakpo S, Egbohou P, Walla K, Pitche P. Is there an association between keloids and blood groups. ISRN Dermatology 2012: 1-4.

15. Bakry OA, Samaka RM, Basha MA, Tharwat A, Meadawy IE. Hemtopoietic stem cells: Do they have a role in keloid pathogenesis? Ultrastruct pathol 2014; 38(1): 55-65

16. Hugle T, White K, M van Laar J. Cell-to-cell-contact of activated mast cells with fibroblasts and lymphocytes in systemic sclerosis. Ann Rheum Dis 2012; 71: 1582-1583.

17. Sarchio SNE, Kok L, O'Sullivan C, Halliday GM, Byrne S, Dermal mast cells affect the development of sunlight -induced skin tumours. Exp Dermatol 2012; 21: 241-248.

18. Zhang W, Wu K, He W et al. Transforming growth factor beta 1 plays an important role in inducing CD4+ CD25+ forhead box P3+ regulatory T cells by mast cells. Clin Exp Immunol 2010; 161: 490-496

19. Beer, T W, Baldwin, H, West L, Gallagher, PJ, Wright, DH. Mast cells in pathological and surgical scars. Br J Ophthamol 1998; 82: 691-694.

20. Moyer KE, Saggers GC, Ehrlich HP. Mast cells promote fibroblast populated collagen lattice contraction through gap junction intercellular communication. Wound Rep Reg 2004; 12: 269-275.

21. Montes GS. Structural biology of the fibers of the collagenous and elastic systems. Cell Biol Int 1996; 20: 1527. 
22. Rich L, Whittaker P. Collagen and picrosirius red staining: A polarized light assessment of fibrillar hue and spatial distribution. Braz J morphol Sci 2005; 22: 97-104.

23. Shaker SA, Ayoub NN, Hajrah NH. Cell Talk: A phenomenon observed in the keloid scar by immunohistochemical study. Appl Immunohistochem Mol Morphol 2011; 9: 153-159.

24. Canty EG and Kadler KE. Procollagen trafficking, processing and fibrillogenesis. J Cell Sci 2005; 118: 13411353.

25. Diegelmann RF, Evans MC. Wound healing: An overview of acute, fibrotic and delayed healing. Frontiers in Bioscience 2004; 9: 283-289.

26. Kadler KE, Baldock C, Bella J, Boot-Handford RP. Collagens at a glance. J Cell Sci 2007; 120: $1955-1958$.

27. Bella J, Liu J, Kramer R, Brodsky B, Bermamn HM. Conformational effects of Gly-X-Gly interruptions in the collagen triple helix. J Mol Biol 2006; 362: 298-311.

28. Hulmes DJS. Building collagen molecules, fibrils and suprafibrillar structures. J Struct Biol 2002; $137:$ 2-10.

29. Greenspan DS. Biosynthestic processing of collagen molecules. Top Curr Chem 2005; 247: 149-183.

30. Brown JC, Timpl R. The collagen superfamily. Int Arch Allergy Immunol 1995; 107:484-490

31. Prockop DJ, Hulmes DJS. Assembly of collagen fibrils de novo from soluble precursors: polymerization and copolymerization of procollagen, pN-collagen, and mutated collagens. Extracellular matrix assembly and structure. Academic Press, New York, NY (1994): 47-90

32. Broder C, Arnold P, Vadon-Le Goff C et al. Metalloproteases meprin $\alpha$ and meprin $\beta$ are $C$ - and Nprocollagen proteinase important for collagen assembly and tensile strength. PNAS 2013; 110 14219-14224.

33. Turtle E, Chow N, Yang C et al. Design and synthesis of procollagen C-proteinase inhibitors. Bioorg Med Chem Lett 2012; 22: 7397-7401.

34. Sansberg N. Accelerated collagen formation and histamine. Nature 1962; 194-183.

35. Ehrlich HP, Desmouliere A, Diegelmann RF et al. Morphological and immunochemical differences between keloid and hypertrophic scar. Am J Pathol 1994; 145:105-113.

36. Muller MM. Inflammation in epithelial skin tumors: Old stories, new ideas. Eur J Cancer. 2006; 42: $735-744$.

37. Rothe MJ, Kerdel FA. The mast cell in fibrosis. Int J Dermatol 1991; 30: 13-16.

38. Plack OJ, Lewis VL. Immunologic association of keloids. Surgical gynaecology and obstetrics 1992;175: 185-193.

39. Gruber BL. Mast cells in the pathogenesis of fibrosis. Curr Rheumatol Rep 2003; 5: 147-153

40. Dvorak AM. Ultrastructural studies of human basophils and mast cells. J Histochem Cytochem 2005; 53: 1043-1070. 
41. Russ SJ, Caughney GH. Mast cells, basophils and eosinophils in the evolution of pulmonary fibrosis. In Pulmonary Fibrosis, Phan SH and Thrall RS, editors Marcell-Decker, Inc. New York. 455-480.

42. Atkins FM, Friedman MM, Pillarisetti V, Subba Rao PV, Metcalfe DD. Interaction between mast cells, fibroblasts and connective tissue components. Int Arch Allergy Appl Immunol 1985; 77: 96-102.

43. Kawanomi O, Ferrans VJ, Fulmer JD, Crystal RG. Ultrastructure of pulmonary mast cells with fibrotic lung disorders. Lab Invest. 1979; 40: 717-734.

44. Heard B, Dewar A, Carrin B. Apposition of fibroblasts to mast cells an lymphocytes in normal human lung and cryptogenic fibrosing alveolitis. Ultrastructure and cell perimeter measurements. J Pathology 1992; 166 : 303-310.

45. Willenborg S, Eckes B, Brinckmann $\mathrm{J}$ et al. Genetic ablation of mast cells redefines the role of mast cells in skin wound healing and bleomycin-induced fibrosis. J Invest Derm 2014; 134: 2005-2015.

46. Luo S, Benathan M, Raffoul W, Panizzon RG, Egloff DV. Abnormal balance between proliferation and apoptotic cell death in fibroblasts derived from keloid lesions. Plast Recontr Surg 2001; 107: 89-96.

47. Smith JC, Boone BE, Opalenik SR, Williams SM, Russell SB. Gene profiling of keloid fibroblasts shows altered expression in multiple fibrosis-associated pathways. J Invest Dermatol 2008; 128: 1298-1310

48. Russell SB, Russell JD, Trupin KM et al. Epigenetically altered wound healing in keloid fibroblasts. $J$ Invest Dermatol 2010; 130: 2489-2496.

49. Mastri M, Shah Z, Hseih K et al. Secreted frizzled-related protein 2 as a target in antifibrotic therapeutic intervention. Am J Physiol Cell Physiol 2013; 306: 531-539.

50. Zhang Z, Nie N, Kang C et al. Increased periostin expression affects the proliferation, collagen synthesis, migration and invasion of keloid fibroblasts under hypoxic conditions. Int J Mol Med 2014: DOI:

10.3892/ijmm.2014.1760 